\title{
Seeds of discord
}

\section{A useful, though partial, survey of how we breed the plants we eat.}

\section{Mendel in the Kitchen: A \\ Scientist's View of Genetically Modified Foods \\ by Nina Fedoroff \& Nancy Marie Brown Joseph Henry Press: 2004. 370 pp. \$24.95, $\mathfrak{E} 17.99(h b k)$}

\section{Margaret E. Smith}

Most people in the industrialized world are blissfully ignorant about plant breeding. Plants provide the food in their supermarkets, flowers to grow in their gardens, and raw materials for industries that produce many items they find useful. Yet people are unaware of plant breeders' efforts over many years to improve the yield and quality of cultivated plants using a growing suite of genetic knowledge and technologies.

The advent of genetically engineered crop plants has, if nothing else, made a certain sector of the public - those who object to such innovations - intensely aware of the discipline of plant breeding. In Mendel in the Kitchen, Nina Fedoroff and Nancy Marie Brown set out to address a number of concerns that have been raised about this most recent addition to the plant breeder's tool-box.

The book provides an informative and engaging description of the history of agricultural science in general, and of plant breeding in particular. The origin of the ambiguous concept of the 'species' is well explained, for instance, highlighting the difficulty of defining the 'traditional species barrier'. Before genetic engineering was possible, cross-breeding was largely limited to plants that are sexually cross-compatible - a criterion that was used to define the limits of a species. Now genetic engineering allows genes to be moved between organisms, regardless of cross-compatibility, so it has been criticized for breaking the species barrier.

The history of other widely accepted plant-breeding tools helps to put genetic engineering in a realistic context. 'Wide crosses' - those between a crop and its wild relatives - are nothing new, nor is the technique of chromosome doubling: the grain triticale, for example, is a product of a wide cross between wheat and rye, followed by doubling the chromosome number to make it fertile. Mutagenesis - using chemical or radiation treatments to cause genetic changes - may sound questionable to some but has been used to produce a few crop varieties that are grown and eaten without concern. Our current agricultural and horticultural plants are far from 'natural' and have been genetically modified by humans

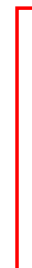

IMAGE UNAVAILABLE FOR COPYRIGHT REASONS

Healthy debate: golden rice may alleviate vitamin A deficiency, but will it reduce rice diversity?

for thousands of years using a broad range of tools, some of them more drastic in their effects than others.

The facts presented in Fedoroff and Brown's book are, for the most part, accurate. It is the things they choose not to include, and the inclusion of some sweeping generalizations, that give the book its decidedly pro-genetic-engineering slant. The omissions may have been meant to minimize detail and complexity, but their accumulated effect is to give the book a distinct bias that people worried about this technology will readily detect.

For example, in a discussion of 'golden rice', which has been genetically engineered to contain beta-carotene in an effort to alleviate vitamin A deficiency, the authors say that concerns about restriction of the gene pool are unfounded. If golden rice proves popular, there is no reason to expect that only one strain will be grown, they argue, as the trait could be bred into any of the thousands of rice varieties grown by farmers at present. This is technically true. However, golden rice is intended to be given to subsistence farmers free of charge, so there is no economic incentive for the private sector to move the beta-carotene genes into thousands of varieties. Public- sector breeding programmes, meanwhile, have neither the personnel nor the financial resources to do so. Initially only a few golden rice varieties will be developed: varieties that have appropriate adaptation, sufficient yields, and acceptable eating quality for the major rice-growing environments. If golden rice is to have the impact on vitamin $\mathrm{A}$ deficiency that its proponents claim, it will need to be very widely grown. That will happen only if these few varieties replace a diversity of existing ones, just as the original 'green revolution' rice varieties did a few decades ago. We now have a sense of the value of that earlier loss of diversity, and should aim to avoid repeating that history.

The authors' approach to the StarLink incident is also enlightening. StarLink corn carries a particular variant of the Bacillus thuringiensis $(B t)$ toxin that the US Environmental Protection Agency (EPA) initially approved for use in animal feed but not as food, pending further research to clarify results that suggested that the $B t$ toxin might have allergenic potential. The authors document this well, along with the subsequent recalls and financial settlements that resulted when StarLink was found in food. But their implication that the EPA, in imposing the restrictions, was somehow responsible for 
the losses incurred by Aventis, the company marketing the StarLink corn, is absurd. Both Aventis and the EPA can be faulted for pretending that corn grown for animal feed could be kept completely separate from corn grown for human consumption. But Aventis chose to market StarLink as animal feed only, rather than waiting to collect the additional data required by the EPA for approval as a food. The issue is not whether data ultimately showed any human food risk from StarLink (in fact, there appears to be no such risk). It is one of public confidence in the regulatory effectiveness of the EPA and in the company's compliance with the restrictions under which it agreed to operate.

Chapter 7 of the book boldly states that we now know that "recombinant DNA technology is among the safest technologies ever developed" - a broad and sweeping claim for a technology that is only a few decades old. In his recent review of Michael Crichton's novel State of Fear (Nature 433, 198; 2005), Myles Allen noted: "A hallmark of good science must be the way it treats uncertainty." In this, Fedoroff and Brown have not been as forthcoming as they should. As a plant breeder, I fully understand the frustration of scientists who are focused on the good that a tool such as genetic engineering can do. However, the agricultural and plantbreeding history that Fedoroff and Brown describe, with its theories that later proved untrue and its technologies that were harmful in unanticipated ways, suggests that a degree of humility would be appropriate. Just as opponents of genetic engineering are unaware of, or are loath to acknowledge, the aspects of this technology that we do understand, such as the genetic history of our cultivated plants, so proponents are reluctant to admit the ambiguities and unknowns about genetic engineering.

As a well-written, engaging account of a controversial subject from a scientist's viewpoint, Mendel in the Kitchen should be on the reading list for everyone interested in genetic engineering, both proponents and opponents. It assembles a large and informative body of information about many of the issues that have raised concerns about genetically engineered crops. However, although the authors state in their introductory chapter, "Which view will seem right to you depends on what you consider conventional, and on how you define the ways of nature," the rest of the book attempts to convince readers that only one view is right.

Margaret E. Smith is in the Department of Plant

Breeding and Genetics, Cornell University,

Ithaca, New York 14853, USA.

\section{More on food and genes}

Genes on the Menu: Facts for Knowledge-Based Decisions

by Paul Pechan \& Gert E. de Vries

Springer, $£ 23, \$ 39.95$, €29.95

\section{Admitting sympathy beyond species}

\section{Thinking with Animals: \\ New Perspectives on \\ Anthropomorphism \\ edited by Lorraine Daston \& \\ Gregg Mitman \\ Columbia University Press: 2005. 240 pp.

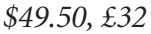 \\ Juliet Clutton-Brock}

When Konrad Lorenz began his studies of animal behaviour in the 1930s, thereby marking the beginnings of ethology as a science, he related the ways of his jackdaws to the ways of people and used highly personal and anthropocentric language. Then, from around the middle of the twentieth century, with the onset of behaviourism, any assumption that animals share the thoughts, feelings or motivations of humans began to be called anthropomorphism. It became a pejorative term applied to the ideas of anyone who dared to believe that animals were capable of conscious thought.

Over the past decades, with the expansion of knowledge about the behaviour of humans and animals, as well as an increased understanding of evolutionary theory, psychologists and philosophers have joined ethologists in research into the minds of animals. This research, known as cognitive ethology, has resulted in many investigations into consciousness, cognition, self-awareness and intelligence, as well as on whether animals feel pain, anger, fear or love, or have a theory of mind. In this context, the title of philosopher Thomas Nagel's essay "What is it like to be a bat?" (in Mortal Questions, Cambridge University Press, 1979) has been much quoted and paraphrased in the ethological literature, including this book.

With cognitive ethology has come the general realization that anthropomorphism does not necessarily disrupt scientific observation but can support the continuity between humans and animals. A strong supporter of this view is Frans de Waal, who proposes the term 'anthropodenial' for the rejection of shared characteristics between humans and animals (The Ape and the Sushi Master, Basic Books, 2001).

On the other hand, there are still those who maintain that anthropomorphism is a distraction from scientific rigour. Over half a century, J. S. Kennedy never wavered from his published view that "if the study of animal behaviour is to mature as a science, the process of liberation from the delusions of anthropomorphism must go on" (The New Anthropomorphism, Cambridge University Press, 1992).

All these points are cited and discussed in the nine eclectic essays in Thinking with

\section{IMAGE UNAVAILABLE FOR COPYRIGHT REASONS}

Rotating photographs of bats turns our perceptions about them upside-down.

Animals, many of which begin with a sentence such as "Anthropomorphism has long been considered a bad word in science". However, as the somewhat contentious title suggests, the main theme of the book is not a further discussion of the now rather jaded arguments for or against the humanizing of animals in science. Instead, it examines the actual practice of anthropomorphism in a wide variety of case studies.

One of the most impressive of these shows how taking an anthropocentric attitude to animals and treating them as individuals can have a dramatic effect on attitudes to animal conservation. In a fascinating account, Gregg Mitman outlines the management of elephants in Kenya. In the 1960s, when 'hard' science ruled, thousands of elephants were killed in order to keep the population within what was considered to be the carrying capacity of Kenya's national parks and reserves. Then, in the 1970s, came the work of Iain DouglasHamilton, followed by many others, to make the public aware of the social life of elephant families. This new perspective led directly to the promotion of the elephant as an endangered species and the banning of the ivory trade.

An essay by the film-maker Sarita Siegel describes how she made a documentary on the work of Anne Russon with orang-utan orphans. This demonstrates the importance for conservation of cooperation between the media and biologists with attitudes 